\title{
IPads Enhance Social Interaction Skills among Hearing-Impaired Children of Low Income Families in Saudi Arabia
}

\author{
Raja Omar Bahatheg ${ }^{1}$ \\ ${ }^{1}$ Early Childhood Education-College of Education, King Saud University, Saudi Arabia \\ Correspondence: Raja Omar Bahatheg, Early Childhood Education-College of Education, King Saud University, \\ Saudi Arabia. E-mail: rbahatheq@gmail.com
}

Received: May 32, 2015 Accepted: July 5, 2015 Online Published: November 26, 2015

doi:10.5539/ies.v8n12p167

URL: http://dx.doi.org/10.5539/ies.v8n12p167

\begin{abstract}
This research tries to investigate the technical contribution on improving the social interaction of hearing-impaired children from low income families in Saudi Arabia. It compares the social interaction skills of hearing-impaired children who do and do not have access to IPads. To achieve the goals of the study; seventeen children aged five-years-old were given access for the first time to iPads to enhance their social skills.

The researcher downloaded 10 educational games on to the iPads and gave each family one iPad whom their child was required to play with the iPad for three hours daily. The researcher used the Child's Social Interaction Scale CSIS as a pre- or post-application measurement to assess the hearing-impaired children's social interaction skills.

Results of the study showed that hearing-impaired children can make all behaviours that are essential to successful social interaction. Also, these children become more sociable, saying thank you, apologising to others, following rules and waiting for a turn. In light of the results, the researcher recommended commercial companies who create games for children to pay attention to hearing-impaired children and develop techniques to help them play with these games in order to develop their interaction social skills alongside normally hearing children.
\end{abstract}

Keywords: IPads, technology device, tablets, low income families, social interaction, Saudi Arabia

\section{Introduction}

The primary process of children's communication is through communicating with others, particularly their parents. Limited research has been conducted about social interaction skills of hearing-impaired children with their peers. The American Speech-Language Hearing Association (ASLHA) stated that hearing-impaired children feel socially isolated, especially when they have a small opportunity to mingle with other hearing-impaired children. ASLHA stated that children experiencing hearing loss or decreased auditory processing tend to be under-identified and lack support, even though it is recognised that hearing plays a crucial role in their social and learning development.

Kaufman (1975) argued that many hearing-impaired children attend their local public schools and integrate with normal children. They have examined the extent that these children interact with their normally hearing peers and are accepted by them. Typically these researchers have found that interaction between hearing-impaired children and their normally hearing peers is minimal; moreover, often (but not always) they are less accepted than their normally hearing classmates.

The important social communication skills that hearing-impaired children may lack are greeting, extending and responding to invitations to join peer activities, cooperating, assisting and conversing with peers. Moreover, researchers as Henggeler and Cooper (1983), Musselman and Churchill (1992), in examining the way of mothers' interaction with their hearing-impaired children have shown a tendency towards brief repetitive exchanges, instead of conversation.

Kubba (2004) demonstrated a link between the extent of hearing-impairment in families and level of income. They found a four-fold difference in incidence between the wealthiest and poorest families. This figure was associated with low birth weight and medical conditions, such as jaundice and hypoxia. Moreover, it was found that those with hearing impairments tended to be unproductive later in life, due to a poorer education and reduced employment prospects. In general, family history and perinatal issues were the two criteria most 
associated with hearing impairment.

As a reality, children, included hearing-impaired children, develop their skills and learn through play. To promote learning there are different curricular options available for them including technology devices that they can use in partnership with adults, such as the iPad and similar Tablet devices. However, this technology is not available to all children, especially those from low-income families.

Mobile technology in the form of mobile phones, Tablets and laptops has enabled learners to access knowledge in new ways, using techniques that are different from traditional methods but also complementary. This technology facilitates autonomous learning in any setting and has been discussed relative to behaviourism, constructivism, socio-cultural, collaborative learning and connectivism, La Greca and Mesibov (1979). Constructive learning focuses on activity, whereby learners construct new ideas and concepts based on their own experiences, solving problems and making decisions, Elser (1959). Socio-cultural awareness can also be facilitated by mobile learning (m-learning) applications that depend on the learner interacting with their social environment, Paivio (2006).

\subsection{Factors That Inhibit Hearing-Impaired Individuals}

Kuzu (2011) conducted a survey examining the factors supporting or inhibiting learners with hearing impairment when employing Personal Digital Assistants (PDA) as a learning medium. Kuzu's study was based on older children than are discussed here. However, the findings are relevant as a key motivator was found to be interactive in daily life, rather than formal instruction; i.e. communicating with friends, Mayberry (2002). One of the key inhibiting consequences of the PDA, was the focus on that rather than on making new friends. This outcome as ASHLA suggests a negative impact on the continued isolation of hearing-impaired individuals. Nevertheless, Rogers (1998) comments that the use of non-verbal stimuli and imagery as a means of guiding learning implicates the application of dual coding principles, inferring that mobile devices would positively affect learning of the hearing- impaired learners.

As Mayberry (2011) notes, hearing-impaired children vary in the extent to which they have problems understanding speech and producing spoken language, Keskin and Metcalf (2011). It is proposed that hearing-impaired children's learning is affected by other variables, such as low socioeconomic status, poor family support or poor comprehension of spoken language, m-learning opportunities would be beneficial. Providing a wide range of support to hearing-impaired children has been proven to lead them to overcome the disadvantages they experience, and leading to academic and life success. As Geers and Morg (1987) note that higher than average IQs and higher than average socioeconomic status characterise those hearing-impaired children who learn to speak best. This advantage leads them to be able to avoid the more extreme consequences of not being able to communicate effectively in speech, Gresham (1982). However; not all hearing-impaired children who have a favourable socioeconomic status and high levels of family support will be able to learn to speak well, although higher levels of support do correlate with higher academic achievements and personal satisfaction, Nicholas and Geers (2007).

\subsection{Question of the Study}

The current study tries to answer the following question:

Is there a statistically significant differences at $(\alpha=0.05)$ between the hearing-impaired children in the experimental and control groups in the social interaction skills due to the use of IPads?

\subsection{Significance of the Study}

This study might provide an insight to change the negative image of using technology in social interaction among hearing-impaired children. It might also help teachers to adopt a more developmental attitude towards the smart electronic devices in classrooms which could be used effectively through adopting modern educational methods.

In addition, this study might provide supervisors and teachers of hearing-impaired children with teaching and communicative techniques and procedures of using new technology to improve the social interaction of the disabled children from low income families in Saudi Arabia. This study would hopefully show whether hearing-impaired children would benefit from electronic games on IPads to improve their oral interactive skills. The participants of the study might benefit from the study to develop their own procedures and techniques in social interactive skills.

Eventually, the lack of local studies in this field had led the researcher to investigate the effect of using IPads to improve the social interactive skills of the Saudi hearing-impaired children from low income families. 
The findings from the present study would be useful in helping decisions makers determined the need for the continued development and expansion of the use of IPads' educational games in special needs' schools settings.

\subsection{Operational Definition of Terms}

A hearing-impaired child: is defined as a child suffering from shortage or loss in the hearing sense (he or she can hear more than 27 decibel, but less than 70), which necessitates the use of aiding tools in order to hear speech (Sisalem, 2002).

IPad: A smart portable tablet with a touch screen .It has the ability to operate the digital games. Also, it has an access to internet.

Low-income family: is the family with low monthly income; between 300-500\$. It has more than four children. The number of qualified males is very minimum; as a result, their job opportunities are very low.

Limitations of the Study: This study was limited to low-income families in Riyadh -Saudi Arabia. Moreover, the study involved the hearing-impaired children in Kindergartens only. It was also confined to social interactive skills of hearing-impaired children. Finally, the study was limited to the educational electronic games downloaded from the British Council's official site.

Validity and reliability of the instruments: To insure the validity of the research instrument, a jury of 3 Child Education university professors, 3 Psychological university professors and 4 special-needs teachers were asked to write their comments on the suitability of the Child's Social Interaction Skills CSIS pre-post observation checklist and the electronic educational games. There comments were taken into consideration in preparing the instruments.

In response to the jury's comments, some games were deleted from the IPads of the experimental group, some were changed and some others were modified.

CSIS validity and reliability were improved by the researchers (Abdul-Magsood \& Al-Sarsee, 2007) .This tool aims to determine the level of social interaction among children. It measures 34 sub social interactive skills. Each paragraph includes a component response of three-verbal (Sometimes- always, rarely).Meeting these requirements of trustworthiness protected the dependability, reliability and authenticity of this research.

\section{Method}

This study was a quasi-experimental one. To answer the study question, the researcher chose two groups; the experimental group which used the IPads to play electronic games, and the control group which had no IPad. Seventeen hearing-impaired children aged five years, from low-income families participated in this project. There were nine children in the experimental group and eight children in the control group. All the children were observed pre and post the experiment using the Child's Social Interaction Skills CSIS measurement which was prepared by Abdul-Magsood and Al-Sarsee (2007). The researcher then divided the children into two groups based on their results on a Draw-A-Man test. This test is a non-verbal test which is used to measure the intelligence of ordinary children, and non-ordinary that between the ages of 4-15 years old. Fuad (1979) codify the scale on the Saudi environment. The researcher used this metric to measure the proportion of variable intelligent participants, for distribution on the two groups to ensure the equality of the two groups in the average IQ.

\subsection{Procedures}

The study sample was chosen purposefully from a low-income society which had not previously an access to a tablet device before this experiment. Moreover, none of the children's families had an internet access at home. After choosing the sample and divided it into two groups, the researcher downloaded (10) educational games from the British Council's kids' official educational site (www.go4english.edu.uk) on the tablets of the experimental group.Then the researcher gave each of the participants a tablet to use at home. The games were the following : (Jewels master, Number link, Unblock Mee, Rings Linking, Sort and Stack Toys 3D,Write with me in Arabic 2, Crazy fruits, Montezuma Puzzle, Zentomino HD, Bubble Mania). Then, the researcher contacted the participants' families via telephone to discuss the idea of the experiment in order to allow their children to use Tablet's games for three hours a day at home. The experimental group played the electronic game using the Tablet device for 14 weeks. The children were observed in school only, and the communication with their teachers was in the classroom.

\subsection{Data Collection}

The researcher used the Child's Social Interaction Skills' CSIS observation checklist which was prepared by Abdul-Magsood and Al-Sarsee (2007). This tool measured hearing-impaired children's social interaction 
skills .It measured four areas: skills and desired behaviours in social interaction; friendship and communication; enjoying playing with others and harmony, isolation and mood when playing separately.

\subsection{Data Analysis}

CSIS was conducted two times during this experiment. Participants were observed pre and post the experiment .Means and Standard Deviations were calculated for the four social interaction skills for the experimental group and the control group following the pre- and post- applications of the CSIS. To determine whether the differences are statistically significant an ANCOVA analysis was performed.

\section{Results}

This portion of the study was dedicated to present the results of CSIS before and after the experiment. Table1 presented means and standard deviations of CSIS of hearing-impaired children.

Table1. Means and standard deviations of social interaction skills CIS of the hearing-impaired children

\begin{tabular}{|c|c|c|c|c|c|}
\hline Child's Social Interaction Skills CSIS & Group & Test & Mean & Std. Deviation & Number \\
\hline \multirow{4}{*}{ Skills and desired behaviours in social interaction } & \multirow{2}{*}{ Cont. } & Pre & 22.5000 & 3.16228 & 8 \\
\hline & & Post & 22.8750 & 4.05101 & 8 \\
\hline & \multirow{2}{*}{ Exper. } & Pre & 15.2222 & 3.56293 & 9 \\
\hline & & Post & 18.2222 & 4.40959 & 9 \\
\hline \multirow{4}{*}{ Friendship and communication } & \multirow{2}{*}{ Cont. } & Pre & 24.6250 & 4.06861 & 8 \\
\hline & & Post & 26.0000 & 4.44008 & 8 \\
\hline & \multirow{2}{*}{ Exper. } & Pre & 15.4444 & 3.84419 & 9 \\
\hline & & Post & 21.1111 & 5.41859 & 9 \\
\hline \multirow{4}{*}{ Enjoying playing with others and harmony } & \multirow{2}{*}{ Cont. } & Pre & 23.3750 & 2.26385 & 8 \\
\hline & & Post & 23.3750 & 2.50357 & 8 \\
\hline & \multirow{2}{*}{ Exper. } & Pre & 20.4444 & 3.28295 & 9 \\
\hline & & Post & 22.5556 & 2.45515 & 9 \\
\hline \multirow{4}{*}{ Isolation and mood when playing separately } & \multirow{2}{*}{ Cont. } & Pre & 7.1250 & .83452 & 8 \\
\hline & & Post & 8.0000 & 1.69031 & 8 \\
\hline & \multirow{2}{*}{ Exper. } & Pre & 8.0000 & 1.00000 & 9 \\
\hline & & Post & 7.4444 & 1.50923 & 9 \\
\hline
\end{tabular}

As it is obvious from Table 1, there was a difference in the average responses of the experimental group in the pre- and post-tests in all four areas of CSIS. The average responses for the experimental group in the post-test were higher than the average responses of pre-test. However, there was no difference between the average responses of the control group in the pre- and post-test. To determine whether the differences are statistically significant an ANCOVA analysis was performed, Table 2 presented ANCOVA results. 
Table 2. ANCOVA analysis of CSIS of hearing-impaired children

\begin{tabular}{|c|c|c|c|c|c|c|}
\hline Source & Dependent Variable & $\begin{array}{l}\text { Type II Sum of } \\
\text { Squares }\end{array}$ & D.f. & $\begin{array}{c}\text { Mean } \\
\text { Square }\end{array}$ & $\mathrm{F}$ & Sig. \\
\hline \multirow{4}{*}{ Group } & Skills and desired behaviours in social interaction & 301.422 & 1 & 301.422 & 20.459 & .000 \\
\hline & Friendship and communication & 419.187 & 1 & 419.187 & 20.718 & .000 \\
\hline & Enjoying playing with other and harmony & 29.779 & 1 & 29.779 & 4.171 & .050 \\
\hline & Isolation and play individually and separately mood & .216 & 1 & .216 & .127 & .724 \\
\hline \multirow{4}{*}{ Test } & $\begin{array}{l}\text { Skills and behaviours desired to happened in social } \\
\text { interaction }\end{array}$ & 24.121 & 1 & 24.121 & 1.637 & .211 \\
\hline & Friendship and communication & 105.004 & 1 & 105.004 & 5.190 & .030 \\
\hline & Enjoying playing with other and harmony & 9.438 & 1 & 9.438 & 1.322 & .259 \\
\hline & Isolation and play individually and separately mood & .216 & 1 & .216 & .127 & .724 \\
\hline \multirow{4}{*}{ Total } & $\begin{array}{l}\text { Skills and behaviours desired to happened in social } \\
\text { interaction }\end{array}$ & 13752.000 & 34 & & & \\
\hline & Friendship and communication & 17024.000 & 34 & & & \\
\hline & Enjoying playing with others and harmony & 17297.000 & 34 & & & \\
\hline & Isolation and mood when playing separately & 2044.000 & 34 & & & \\
\hline
\end{tabular}

Table 2 shows statistically significance differences at $(\alpha=0.05)$ between the average responses of experimental group members for skills and desired behaviours in CSIS; friendship and communication; and, enjoying playing with others and harmony. While there was no statistically significant differences at $(\alpha=0.05)$ for isolation and mood when playing separately. The average difference between the two groups is presented in Table 3 .

Table 3. Means and standard deviations of CSIS pre-post observations of the impaired-hearing children

\begin{tabular}{llll}
\hline Group & Observ. & Mean & Std. Deviation \\
\hline \multirow{2}{*}{ Skills and desired behaviours in social interaction } & Pre & 15.22 & 3.56 \\
& Post & 19.72 & 4.40 \\
Friendship and communication & Pre & 15.44 & 3.84 \\
& Post & 21.79 & 5.41 \\
Enjoying playing with others and harmony & Pre & 20.44 & 3.28 \\
& Post & 22.44 & 2.45 \\
Isolation and mood when playing separately & Pre & 8.00 & 1.00 \\
& Post & 7.64 & 1.50 \\
\hline
\end{tabular}

Table 3 presented the significant results of the post-test, which implies a relationship between the use of Tablet devices and social interaction among hearing-impaired children in terms of skills and desired behaviours in social interaction and friendship and communication. The results showed no significant statistical differences at $(\alpha=0.05)$ between the average responses of the two groups in the areas of enjoying playing with others and harmony and isolation and mood skills when playing separately. Obviously, the suggested Tablet use did not impact on these criteria. The researcher also compared the means and standard deviations of the two groups of hearing-impaired children who participated in the current study. Table 4 presented the results. 
Table 4. Means, standard deviations and standard error means of CSIS of hearing-impaired children

\begin{tabular}{lccccc}
\hline CSIS & \multirow{2}{*}{ Group } & N & Mean & $\begin{array}{c}\text { Std. } \\
\text { Deviation }\end{array}$ & $\begin{array}{c}\text { Std. Error } \\
\text { Mean }\end{array}$ \\
\hline \multirow{2}{*}{ Skills and desired behaviours in social interaction } & Exper & 9 & 22.6875 & 3.51603 & .87901 \\
& Cont & 8 & 16.7222 & 4.18408 & .98620 \\
Friendship and communication & Exper & 9 & 25.3125 & 4.17483 & 1.04371 \\
& Cont & 8 & 18.2778 & 5.41029 & 1.27522 \\
Enjoying playing with other and harmony & Exper & 9 & 23.3750 & 2.30579 & .57645 \\
& Cont & 8 & 21.5000 & 3.01467 & .71056 \\
Isolation and mood when playing separately & Exper & 9 & 7.5625 & 1.36473 & .34118 \\
& Cont & 8 & 7.7222 & 1.27443 & .30039 \\
\hline
\end{tabular}

Table 4 revealed a difference between the mean responses of the two groups regarding skills and desired behaviours in social interaction (22.687 for the experimental group and 16.722 for the control group). In the area of friendship and communication for social interaction $(\mathrm{m}=25.31$ for the experimental group and $\mathrm{m}=18.277$ for the control group).The mean responses in the area of enjoying playing with others and harmony were (23.275 for the experimental group and 21.50 for the control group).However, the mean responses in the post-test for isolation and mood when playing separately (7.562 for the experimental group and 7.722 for the control group). To discover whether these differences were statistically significant a T-test analysis was performed. Results are presented in Table 5 .

Table 5. T-test of CSIS of hearing-impaired children

\begin{tabular}{|c|c|c|c|c|c|}
\hline Social Interaction Skills & t. & Df & $\begin{array}{l}\text { Sig. } \\
\text { (2-tailed) }\end{array}$ & $\begin{array}{c}\text { Mean } \\
\text { Difference }\end{array}$ & $\begin{array}{l}\text { Std. Error } \\
\text { Difference }\end{array}$ \\
\hline $\begin{array}{l}\text { Skills and desired behaviours in social } \\
\text { interaction }\end{array}$ & 4.469 & 32 & .000 & 5.96528 & 1.33495 \\
\hline Friendship and communication & 4.204 & 32 & .000 & 7.03472 & 1.67341 \\
\hline Enjoying playing with other and harmony & 2.017 & 32 & .052 & 1.87500 & .92963 \\
\hline Isolation and mood when playing separately & $-.353-$ & 32 & .727 & $-.15972-$ & .45269 \\
\hline
\end{tabular}

Table 5 exhibited a significant statistical difference at $(\alpha=0.05)$ between the control and experimental groups for skills and desired behaviours in social interaction and friendship and communication. This result indicated the effectiveness of using the Tablet device with hearing-impaired children to improve their social interactions. However, Table 5 showed no statistically significant differences between the experimental and control groups in the areas of skills enjoying playing with others and harmony and isolation and mood when playing separately. This result designated that the suggested Tablet device is not useful in this regard.

\section{Discussion}

Hearing-impaired children live in a physical environment that is designed for hearing people. This reality represented multiple challenges to them. The purpose of this research was to demonstrate the effectiveness of Tablet devices on hearing-impaired children's social interaction. Simms and Thumann (2007) noted that 
hearing-impaired children have not often been the target of general education research. As a result, this research tried to introduce this area for further study.

Vincenta (2007) argued that environmental factors include both physical and social aspects. Social environmental factors include elements such as the support and attitudes of family and friends, whereas physical environmental factors refer to natural elements or technology. Through connecting the physical and social environment, this research found that Tablet devices assist in the development of hearing-impaired children's social interaction skills. Tablet devices helped the learners to develop hearing-impaired friendships and to improve their skills and desired behaviours in social interaction. Though; they did not help to develop hearing-impaired children's skills in enjoying playing with others.

The importance of social interaction is emphasised by Hay and DeLuzio (2004), and Kennedy (1989), who debated that children's engagement in social interaction during their play with other children contributed to their social, emotional, and academic development. Furthermore, when hearing-impaired children integrated with their normal hearing peers in preschool, their play and interaction were nonlinguistic, which is similar to the situation when children play together using Tablets, Deluzio, and Girolamet (2011).

The current study found that hearing-impaired children can make all behaviours that are essential to successful social interaction. For instance; they can make friends and comunicate with them through asking them how to play games using the Tablet. Also, these children become more sociable, saying thank you, apologising to others, following rules and waiting for a turn. According to Nicholas amd Geers (2007), and Preisler, Tvingstedt, and Ahlstrom (2002), it is difficult for non hearing-impaired children to communicate with their hearing-impaired peers and to develop social interactions between them. Thus, it is of value that the data presented in this research found that playing educational games on a Tablet device can facilitate communication between hearing-impaired and non hearing-impaired children.

As mentioned above, some improvements were noted in the hearing-impaired children's in the areas of skills and desired behaviours in social interaction and friendship and communication. However, these children still preferred to spend most of their time playing alone and did not report enjoying playing with others. Bat-Chava and Deignan (2001) agreed that socialisation's abilities in children can progress at different rates. It is acknowledged that hearing-impaired children vary in their ability to accomplish social tasks (Preisler, 2002; Antia \& Kreimeyer, 1996). In addition, Rieffe and Terwogt (2006), Drew and Temblay (1979), Bruner (1966), Burton and Lybarger (1998), Levy-Shift and Hoffman (1985) have reported that forming friendships in the classroom setting is more difficult for hearing-impaired children Antia (2010). This is a difficulty that does not only relate to friendships involving hearing-impaired children and their normally hearing peers, it is also the case in friendships where both parties are hearing-impaired (Arthur, 1993; Antia, 1982; Munes et al., 2001; Kennedy, 1979). It is thought that difficulties with friendships may stem from these children's more limited grasp of social rules and the goals of friendship, or from a tendency to attribute negative intentions to their peers Amy and Lederbreg (1987).

The evidence from these studies may explain why the hearing-impaired children in this study revealed a preference for playing alone and had a difficulty in interacting and taking turns during play, as shown in Tables 4 and 5. It was also observed that the children did not want to listen to one another, or participate in dancing or singing activities because of their disability. They also did not pay attention to rules and avoided following them, thus, in spite of the intervention, they found it easier to play separately from their peers.

\section{Conclusion and Recommendations}

Rogers (1998) said that "Networked computers give hearing-impaired people the same access to the rich variety of information that shapes and defines the society without a need for the special services or adaptive devices which are necessary to make most mainstream communication technologies accessible". In light of the results of the current study, the researcher recommended the commercial companies who create games for children to pay attention to this group of hearing-impaired children and develop techniques to help them play with these games which will develop their skills alongside with normally hearing children.

\section{Acknowledgements}

This is a research project that was supported by a grant from the Research Centre for the Humanities, Deanship of Scientific Research at King Saud University

\section{References}

Abdul-Magsood, A., \& Al-Sarsee, A. (2007). Child's Social Interaction Scale. CSIS, Egypt: The Egyptian Anglo Press 
Amy, R., \& Lederberg, E. (1987). Temporary and long term friendships in hearing and hearing-impaired pre-schoolers. Merrill-Palmer Quarterly, 33, 515-533.

Antia, J. (2010). Social interaction. Education, 23, 12-18.

Antia, Sh. (1982). Social interaction of partially mainstreamed hearing-impaired children. American Annals of the Hearing-impaired, 127, 18-25. http://dx.doi.org/10.1353/aad.2012.1184

Antia, Sh., \& Kreimeyer, K. (1996). Social interaction and acceptance of hearing-impaired or hard-of-hearing children and their peer: A comparison of social skills and familiarity-based interventions. Volta Review, 98, 157-180.

Arthur, N., Schildroth, B., \& Sue, A. (1993). Annual of hearing-impaired children and youth. American Annals of the Hearing-impaired, 138, 171-178.

Bat-Chava, Y., \& Deignan, E. (2001). Peer relations of children with cochlear implants. Journal of Hearing-impaired Studies and Hearing-impaired Education, 6, 186-199.

Bruner, J. (1966). Toward a Theory of Instruction. Cambridge: Harvard University Press.

Burton, T., \& Lybarger, R. (1998). An attributional analysis of aggression among children who are hearing-impaired. Journal of the American Hearing-impairedness and Rehabilitation Association, 31, $10-22$.

DeLuzio, J., \& Girolamet, L. (2011). Peer Interactions of Preschool Children With and Without Hearing Loss. Journal of Speech, Language, and Hearing Research, 54, 1197-1210. http://dx.doi.org/10.1044/1092-4388(2010/10-0099)

Drew, A., \& Tremblay, A. (1979). Interaction of hearing-impaired and hearing pre school children. Journal of Communicative Disorders, 12, 245-251. http://dx.doi.org/10.1016/0021-9924(79)90045-5

Elser, R. (1959). The social position of hearing handicapped children in the regular grades'. Exceptional Children, 25, 305-309.

Fougeyrollas, P. (1998). Social consequences of long term impairments and disabilities: Conceptual approach and assessment of handicap. International Journal of Rehabilitation Research, 21, 127-141. http://dx.doi.org/10.1097/00004356-199806000-00002

Geers, A., \&Morg, J. (1987). Predicting spoken language acquisition of profoundly hearing-impaired children. Journal of Speech and Hearing Disorders, 52, 84-94. http://dx.doi.org/10.1044/jshd.5201.84

Gresham, F. (1982). Misguided mainstreaming: The case for social skills training with handicapped children. Exceptional Children, 48, 422-433.

Hay, D., Payne, A., \& Chadwick, A. (2004). Peer relations in childhood. Journal of Child Psychology and Psychiatry, 45, 84-108. http://dx.doi.org/10.1046/j.0021-9630.2003.00308.x

Henggeler, S., \& Cooper, P. (1983). Hearing-impaired child hearing mother interaction: Extensiveness and reciprocity. Journal of Paediatric Psychology, 8, 83-98. http://dx.doi.org/10.1093/jpepsy/8.1.83

Kaufman, J. (1975). Mainstreaming: Toward an explication of the construct. Focus on Exceptional Children, 7 , $1-13$.

Kennedy, A. (1989). Mainstreaming hearing-impaired children. British Journal of Educational Psychology, 65, 11-18.

Kennedy, P. (1976). Longitudinal sociometric and cross and cross-sectional data on mainstreaming hearing-impaired children: Implications for pre school planning. The Volta Review, 78, 71-81.

Keskin, N., \& Metcalf, D. (2011). The current perspectives, theories and practices of mobile learning. Turkish Online Journal of Educational Technology, 10, 202-208.

Kubba, H. (2004). Is hearing-impairedness a disease of poverty? The association between socio-economic deprivation and congenital hearing impairment. International Journal of Audiology, 43, 123-125. http://dx.doi.org/10.1080/14992020400050017

Kuzu, A. (2011). The Factors That Motivate And Hinder The Students With Hearing Impairment To Use Mobile Technology. TOJET, 10, 336-348.

La Greca, M., \& Mesibov, G. (1979). Social skills intervention with learning disabled children: Selecting skills and implementing training. Journal of Clinical Child Psychology, 8, 234-241. 
http://dx.doi.org/10.1080/15374417909532928

Levy-Shift, R., \& Hoffman, M. (1985). Social behaviour of hearing-impaired and normally hearing pre schoolers. British Journal of Educational Psychology, 55, 111-118. http://dx.doi.org/10.1111/j.2044-8279.1985.tb02615.x

Mayberry, J. (2011). Cognitive development. Child's Development Quarterly Journal, 34, 56-62.

Mayberry, R. (2002). Cognitive development in hearing-impaired children: The interface of language and perception. Neuropsychology Journal, 22, 34-39.

Musselman, C., \&Churchill, A. (1992). The effects of maternal conversational control on the language and social development of hearing-impaired children, Journal of Childhood Communication Disorders, 14, 99-117. http://dx.doi.org/10.1177/152574019201400201

Nicholas, J., \&Geers, J. (2007). Will they catch up? The role of age cochlear implantation in the spoken language development of children with severe to profound hearing loss. Journal of Speech, Language, and Hearing Research, 50, 1048-1062. http://dx.doi.org/10.1044/1092-4388(2007/073)

Nunes, T., Pretzlik, U., \& Olsson, J. (2001). Hearing-impaired children's social relationships in mainstream schools. Hearing-impairedness and Education International, 3, 123-136.

Paivio, A. (2006). Dual Coding Theory And Education. In Proceedings of Conference on 'Pathways to Literacy Achievement for High Poverty Children' The University of Michigan School of Education, U.S.A (pp. 1-20).

Preisler, G., Tvingstedt, A., \& Ahlström, M. (2002). Psychosocial follow-up study of hearing-impaired preschool children using cochlear implants. Child: Care, Hwalth and Development, 28, 403-418. http://dx.doi.org/10.1046/j.1365-2214.2002.00291.x

Rieffe, C., \& Terwogt, M. (2006). Anger communication in hearing-impaired children. Cognition and Emotion, 20, 1261-1273. http://dx.doi.org/10.1080/02699930500513502

Rogers, T. (1998). Access to information on computer networks by the deaf. Communication Review, 2, 497-503. http://dx.doi.org/10.1080/10714429809368569

Simms, L., \& Thumann, H. (2007). In search of a new linguistically and culturally sensitive paradigm in deaf education. American Annals of the Deaf, 152, 302-311. http://dx.doi.org/10.1353/aad.2007.0031

Sisalem, K. (2002). Special education and psychological rehabilitation encyclopedia. Cairo: Dar al-kitab Al-Jamie Publisher.

Vincenta, C., Deaudelina, I., \& Hottonc, M. (2007). Pilot on evaluating social participation following the use of an assistive technology designed to facilitate face-to-face communication between deaf and hearing persons. Technology and Disability, 19, 153-167.

\section{Copyrights}

Copyright for this article is retained by the author(s), with first publication rights granted to the journal.

This is an open-access article distributed under the terms and conditions of the Creative Commons Attribution license (http://creativecommons.org/licenses/by/3.0/). 